\title{
A EXPERIMENTAÇÃO EM FOCO: O QUE PENSAM OS LICENCIANDOS SOBRE O TEMA? ${ }^{1}$
}

\section{THE EXPERIMENTATION IN FOCUS: WHAT DO THE STUDENTS THINK ABOUT THE THEME?}

\author{
CARNEIRO, Marcelo Carbone ${ }^{2}$ \\ PRADO, Letícia do ${ }^{3}$
}

\begin{abstract}
RESUMO
A carga horária de um curso de licenciatura em química prevê cerca de $50 \%$ de atividades didático experimentais. Além disto, muitos alunos envolvem-se em projetos de iniciação científica cuja a experimentação é rotina. Neste cenário desenvolvemos esta pesquisa, na qual solicitamos a uma turma de licenciandos em química que escrevessem palavras, frases ou expressões que pudessem ser associadas a: "experimentação", "experimentação em laboratório de pesquisa" e "experimentação em laboratório didático". Nosso objetivo era compreender e delimitar quais concepções permeavam o entendimento destes futuros professores sobre a experimentação para o ensino de química e para a química como ciência particular. Interpretamos os dados obtidos usando como suporte a análise fenomenológica. Em todas as respostas, a experimentação foi associada a uma visão kuhniana, pouco crítica, fechada e utilitarista de ciência. Sendo mais recorrente a generalização da experimentação como comprovação de teorias.
\end{abstract}

Palavras-Chave: Experimentação; Formação Inicial de Professores; Ensino de Química.

\begin{abstract}
The hours of a bachelor's degree in chemistry provide about $50 \%$ of experimental didactic activities. In addition, many students are involved in scientific initiation projects whose experimentation is routine. In this scenario we developed this research, in which we asked a class of chemistry graduates to write words, phrases or expressions that could be associated with: "experimentation", "experimentation in the research laboratory" and "experimentation in the didactic laboratory". Our objective was to understand and delimit which conceptions permeated the understanding of these future teachers about experimentation for the teaching of chemistry and for chemistry as a particular science. We interpret the data obtained using phenomenological analysis. In all responses, experimentation was associated with a Kuhnian, uncritical, closed, and utilitarian view of science. Being more frequent the generalization of the experimentation as proof of theories
\end{abstract}

KEYWORDS: Experimentation; Initial Teacher Training; Chemistry teaching.

1 O presente trabalho foi realizado com apoio da Coordenação de Aperfeiçoamento de Pessoal de Nível Superior - Brasil (CAPES) - Número do processo: 1678703.

2 Professor Adjunto do Departamento de Ciências Humanas da Universidade Estadual Paulista (UNESP), Faculdade de Arquitetura, Artes e Comunicação, Campus de Bauru - SP. e-mail: carbone@faac.unesp.br

${ }^{3}$ Doutoranda e Mestre pelo Programa de Pós-Graduação em Educação para Ciência da Faculdade de Ciências da Universidade Estadual Paulista, Campus de Bauru - SP. e-mail: leticiadpd@gmail.com 


\section{INTRODUÇÃO}

A experimentação é uma estratégia didática do ensino de química que propicia momentos de interpretação, generalização e previsão de teorias a partir da observação e discussão sobre os fenômenos contidos na proposta de trabalho do professor. Destacam-se três principais abordagens para o uso da experimentação, as propostas de demonstração, verificação e investigação. Elas podem ser apresentadas aos alunos de forma separada ou integrada como no caso das atividades demonstrativas-investigativas propostas por Silva et al (2011). Há vertentes de estudo que afirmam que a experimentação além de promover o aprendizado de conceitos científicos, melhora a capacidade de observação, registro de informações e elaboração de hipóteses, sendo aliada na correção de erros conceituais dos alunos e em seu desenvolvimento pessoal. Com isso, o aluno é capaz de desenvolver a capacidade de trabalhar em grupos, tomar decisões e tem sua criatividade estimulada pela via da motivação (OLIVEIRA, 2010). Porém, defendemos que apenas propor experimentos não é suficiente, para abarcar todos estes benefícios listados acima, faz-se necessário que o professor avalie as estratégias, abordagens, objetivos, recursos e as perguntas que darão subsídios para a prática experimental.

Oliveira (2010) por exemplo, argumenta que a experimentação deve ser apresentada segundo níveis de dificuldade, assim alunos mais inexperientes devem ser apresentados a propostas experimentais de verificação e demonstração para que assim possam familiarizar-se com o recurso didático e suas particularidades. Desta forma, quando mais experientes, eles poderão tomar conta de suas próprias investigações em experimentos do tipo resolução de problemas. Outro aspecto importante a se destacar, e que todos devem ter em mente, é que a experimentação assume diferentes objetivos segundo o ambiente em que ela é praticada.

Quando praticada em laboratórios de pesquisa, por exemplo, a observação é um procedimento condicionado por aquilo que já se sabe e direcionado pelas perguntas dos pesquisadores, que produzem conhecimentos científicos que devem ser validados e reconhecidos por toda a comunidade científica (ESPINOZA, 2010).

Em contraposição, a experimentação com objetivos didáticos é proposta por um indivíduo que já conhece a resposta do experimento, ou seja, o professor proporciona aos alunos a oportunidade de observar, fazer generalizações e previsões sobre determinado fenômeno. Em alguns casos, ele orienta caminhos para que seus alunos proponham experimentos adequados para o teste de suas hipóteses.

Independentemente de quem propõe o experimento didático ou da forma como ele é trazido, é necessário que o aluno entenda qual o propósito da atividade por que se deve registrar, formular hipóteses, testá-las, responder questões, formular conclusões ou explicações sobre o fenômeno estudado para que assim se aprenda sobre determinado conhecimento. Sabendo disto, investigamos neste trabalho como os alunos de um curso de licenciatura em química definiam, segundo suas vivências, os termos: "experimentação", "experimentação em laboratório de 
e-Mosaicos - Revista Multidisciplinar de Ensino, Pesquisa, Extensão e Cultura do Instituto de Aplicação Fernando Rodrigues da Silveira (CAp-UERJ)

V. 7 - N. 16 - DEZEMBRO 2018 - ISSN: 2316-9303

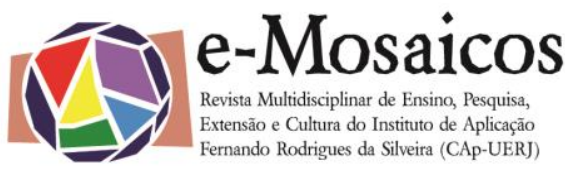

DOI: $10.12957 /$ e-mosaicos.2018.38675

pesquisa" e "experimentação em laboratório didático". Nosso objetivo era, a partir da análise destas respostas, poder delimitar o que pensavam os futuros professores de química sobre o papel da experimentação para o ensino de química e para química como ciência particular.

\section{A FENOMENOLOGIA COMO RECURSO METODOLÓGICO}

Utilizamos como fonte de informações para este estudo parte de um questionário usado para levantamento das concepções prévias dos alunos sobre o tema da aula "A experimentação como metodologia para o ensino de química", ministrada em um curso de licenciatura em química de uma universidade pública.

Nesta atividade dividimos uma folha de papel em três e partes e solicitamos que os alunos escrevessem palavras, frases ou expressões que se relacionassem aos termos: 1. experimentação, 2. experimentação em laboratório de pesquisa e 3. experimentação em laboratório didático. Para tratar e analisar o material gerado pelos alunos usamos a análise fenomenológica como metodologia suporte.

A fenomenologia é o estudo das essências, busca-se com ela compreender o homem e o mundo a partir de sua facticidade, ou seja busca-se por uma descrição direta de nossa experiência tal como ela é (MERLEAU-PONTY, 1999). Há de se ter em mente que as essências não são o fim da análise, elas são meios de trazer à luz todas as relações vividas pelo sujeito. Para extrair a essência, o pesquisador não deve possuir princípios explicativos, teorias ou qualquer indicação definidora, mas deve iniciar seu trabalho interrogando o próprio fenômeno. Nas palavras de Martins e Bicudo (1989, p. 92), O fenomenólogo respeita as dúvidas existentes sobre o fenômeno pesquisado e procura mover-se lenta e cuidadosamente de forma que ele possa permitir aos seus sujeitos trazerem à luz do sentido por eles percebidos sobre o mesmo.

Esta metodologia aplicada à pesquisa qualitativa em educação, pressupõe que o fenômeno não se esgota, e o pesquisador deve buscar convergências dentro do conjunto de significados a ele revelados. Neste âmbito buscamos entender, a partir das respostas dadas por licenciandos em química, qual o papel da experimentação no ensino de química e na química como ciência particular. Segundo Martins e Bicudo (1989), após a coleta dos dados, o pesquisador deve seguir quatro passos metodológicos, simplificadamente podemos defini-los como: 1. Dar sentido ao todo: ler os dados coletados de modo a familiarizar-se com a linguagem usada pelos sujeitos. 2. Definir as unidades de significado: neste momento o pesquisador deve reler os dados buscando por unidades norteadoras para a análise. 3. Criar categorias de análise, transformando as expressões dos sujeitos em uma linguagem concreta e separada pelas suas similaridades. 4. Sintetizar as unidades de significado: 0 pesquisador deve produzir um texto ou metatexto em que são expressas as compreensões acerca do fenômeno investigado. A criação de categorias de análise (passos 3 e 4) podem ser nomeadas pela fenomenologia como análise ideográfica e análise nomotética. A análise ideográfica tem como objetivo organizar os trechos 
DOI: $10.12957 /$ e-mosaicos.2018.38675

relevantes das respostas dos sujeitos através da leitura exaustiva dos questionários/transcrições coletadas na pesquisa. Trata-se de um movimento analítico que tem como referência o agrupamento de ideias que convergem para uma mesma unidade de significado (BASTOS, 2017).

A análise nomotética é uma síntese integrativa, que possibilita reagrupar as representações levantadas pela análise ideográfica e generalizar seus aspectos individuais. Naturalmente não se tratam de generalizações universais, mas generalizações contextuais no âmbito do fenômeno estudado (BASTOS, 2017).

Ambas as análises compõem o texto de fechamento, cuja função é interpretar as generalizações, provenientes das proposições expressas acerca das compreensões dos sujeitos em relação ao fenômeno estudado.

\section{OS DADOS COLETADOS E SUAS GENERALIZAÇõES}

Nos quadros 1, 2 e 3, a seguir, apresentamos os dados obtidos e as análises feitas a partir das respostas dos alunos. Para preservar o anonimato, substituímos os nomes pela abreviação "Lic." (de licenciando) seguida de um número de 1 a 5 . Na segunda coluna apresentamos as convergências das respostas, ou seja, a análise ideográfica. Nela as expressões separadas por barra são oriundas do mesmo sujeito.

A terceira coluna tem por objetivo apresentar a análise nomotética, ou seja, a generalização e caracterização das ideias convergentes presentes nas respostas dos alunos. As respostas foram organizadas em ordem decrescente de recorrência, assim podemos facilmente visualizar, além das informações já descritas, quais as convergências e generalizações mais se repetiram.

Quadro 1. Organização das respostas dos alunos sobre o tema "Experimentação"

\begin{tabular}{|c|c|c|}
\hline Código & Convergências & Generalizações \\
\hline $\begin{array}{l}\text { Lic.1, } \\
\text { Lic.3, } \\
\text { Lic.5. }\end{array}$ & $\begin{array}{l}\text { "Experimentação é a comprovação da teoria"; } \\
\text { "Visualização da prática da teoria"; "O que era para } \\
\text { acontecer? Acho que deu errado/ Mudou de cor, deu } \\
\text { certo"; "Algo visual para explicar a teoria"; "Associação } \\
\text { ao conhecimento empírico obtido através das aulas". }\end{array}$ & $\begin{array}{l}\text { Comprovação } \\
\text { teorias }\end{array}$ \\
\hline $\begin{array}{l} \\
\text { Lic.2, } \\
\text { Lic.5. }\end{array}$ & $\begin{array}{l}\text { "Relatório/ Artigo"; "Depois do laboratório a gente } \\
\text { conversa muito sobre o que viu antes de escrever o } \\
\text { relatório"; "Relatórios elaborados antes e depois do } \\
\text { experimento". }\end{array}$ & $\begin{array}{lr}\text { Necessidade } & \text { de } \\
\text { sistematizar } & 0 \\
\text { observado de forma } \\
\text { escrita. }\end{array}$ \\
\hline $\begin{array}{l}\text { Lic.1; } \\
\text { Lic.5. }\end{array}$ & $\begin{array}{l}\text { "Parte do que ocorre na natureza pra dentro do } \\
\text { laboratório"; "Trazer o conceito para algo do } \\
\text { cotidiano"; "Práticas que podem ser representações de } \\
\text { experiências vividas no dia a dia". }\end{array}$ & $\begin{array}{l}\text { Observação de } \\
\text { fenômenos do cotidiano }\end{array}$ \\
\hline Lic. 4. & $\begin{array}{l}\text { "Prática, laboratório, teste de chama, cromatografia, } \\
\text { titulação". }\end{array}$ & $\begin{array}{l}\text { Associação ao lugar de } \\
\text { realização/métodos/equ } \\
\text { ipamentos }\end{array}$ \\
\hline
\end{tabular}

Fonte: Nossa autoria. 
e-Mosaicos - Revista Multidisciplinar de Ensino, Pesquisa, Extensão e Cultura do Instituto de Aplicação Fernando Rodrigues da Silveira (CAp-UERJ)

V. 7 - N. 16 - DEZEMBRO 2018 - ISSN: 2316-9303

DOI: $10.12957 /$ e-mosaicos.2018.38675

Quadro 2. Organização das respostas dos alunos sobre o tema "Experimentação em laboratório de pesquisa"

\begin{tabular}{|c|c|c|}
\hline Código & Convergências & Generalizações \\
\hline $\begin{array}{l}\text { Lic.1; Lic.2; } \\
\text { Lic.3; Lic.4. }\end{array}$ & $\begin{array}{l}\text { "Cobrança de resultados"; "Análises/ Artigos"; } \\
\text { "Relatório/ Artigo";, "Obter resultados". }\end{array}$ & $\begin{array}{l}\text { Necessidade de } \\
\text { sistematizar o } \\
\text { observado de forma } \\
\text { escrita. }\end{array}$ \\
\hline $\begin{array}{l}\text { Lic.3; Lic.4; } \\
\text { Lic.5. }\end{array}$ & $\begin{array}{l}\text { "Mudou de cor, deu certo"; "Estudar a teoria, ter } \\
\text { dados"; } \\
\text { "Pode contribuir para um maior aprofundamento de } \\
\text { teorias ou até mesmo práticas apresentadas e } \\
\text { realizadas" }\end{array}$ & Comprovação de teorias \\
\hline Lic. 1; Lic. 2. & $\begin{array}{l}\text { "Parte do que faremos no mercado de } \\
\text { trabalho/Inovação"; "Desenvolvimento/Elevar a } \\
\text { economia do país". }\end{array}$ & $\begin{array}{l}\text { Tecnologias de inovação } \\
\text { e produção para o } \\
\text { mercado de trabalho }\end{array}$ \\
\hline Lic.1. & "Instrumentos complexos". & $\begin{array}{l}\text { Associação ao lugar de } \\
\text { realização/métodos/test } \\
\text { es/equipamentos }\end{array}$ \\
\hline
\end{tabular}

Fonte: Nossa autoria.

Quadro 3. Organização das respostas dos alunos sobre o tema "Experimentação em laboratório didático".

\begin{tabular}{|l|l|l|}
\hline \multicolumn{1}{|c|}{ Código } & \multicolumn{1}{|c|}{ Convergências } & \multicolumn{1}{c|}{ Generalizações } \\
\hline Lic.1; Lic.2; \\
Lic.3; Lic.4, \\
Lic.5. & $\begin{array}{l}\text { "Comprovar teoria/Entender Processos/ Tanto faz é só } \\
\text { para observar"; "Era para ter ficado rosa, ficou preto"; } \\
\text { "Aprendizagem e entendimento visual da teoria"; "O } \\
\text { que era para acontecer? Acho que deu errado"; } \\
\text { "Entender a teoria, prática, aplicar o estudado"; } \\
\text { "Procedimentos conhecidos pelos professores que } \\
\text { podem ser realizados pelos alunos". }\end{array}$ & $\begin{array}{l}\text { Experimento } \\
\text { comprovaço de teorias }\end{array}$ \\
\hline Lic.2; Lic.3. & $\begin{array}{l}\text { "Relatório"; "No final de cada aula tem o relatório para } \\
\text { entregar". }\end{array}$ & $\begin{array}{l}\text { Ressaltam a } \\
\text { necessidade de elaborar } \\
\text { relatórios como principal } \\
\text { atividade da } \\
\text { experimentação }\end{array}$ \\
\hline Lic.3; Lic.5. & $\begin{array}{l}\text { "Como faz esse? Fica Colorido?"; "As vezes tem } \\
\text { procedimentos que não conhecemos". }\end{array}$ & $\begin{array}{l}\text { Roteiros fechados . } \\
\text { Lic.1. }\end{array}$ \\
"Gambiarra. Saber identificar. Reagentes vencidos. & $\begin{array}{l}\text { Associação a } \\
\text { métodos/testes/equipa } \\
\text { mentos }\end{array}$ \\
\hline
\end{tabular}

Fonte: Nossa autoria.

Como podemos ver no quadro 1 , todos os alunos escreveram frases e/ou expressões que relacionavam o termo "Experimentação" à ideia de comprovação de teorias. Em segundo lugar dos mais citados, ficaram as relações entre a experimentação e a necessidade de sistematização do observado de forma escrita e a possibilidade de fazer observações de fenômenos do cotidiano. Somente um aluno 
e-Mosaicos - Revista Multidisciplinar de Ensino, Pesquisa, Extensão e Cultura do Instituto de Aplicação Fernando Rodrigues da Silveira (CAp-UERJ)

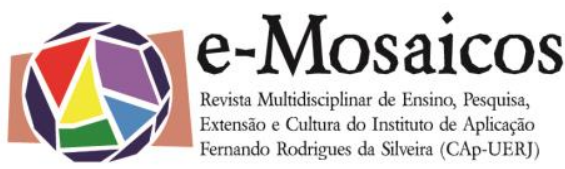

DOI: $10.12957 /$ e-mosaicos.2018.38675

associou o termo ao local onde a experimentação é realizada e a metodologias e técnicas realizadas no âmbito dos laboratórios de química.

No quadro 2, a "Experimentação em laboratório de pesquisa" foi mais associada à necessidade de sistematizações escritas e obtenção de dados analisáveis. Em segundo lugar, está a proposição de que neste ambiente se promove a comprovação de teorias ao mesmo tempo que, em terceiro lugar, destaca-se termos como inovação e desenvolvimento ou atividade do mercado de trabalho. Assim como no quadro 1 , somente um aluno associou o ambiente a um método/teste/equipamento através da expressão "instrumentos complexos".

As respostas sobre "Experimentação em laboratório didático" apresentadas no quadro 3, também foram unânimes em associar este ambiente à comprovação de teorias. Na sequência dois alunos ressaltaram elaboração relatórios como atividade essencial neste ambiente, sugerindo também que, em laboratórios didáticos, são trazidos procedimentos desconhecidos que por vezes provocam muitas dúvidas. É interessante destacar que o mesmo aluno que, no quadro 2, associou o ambiente a técnicas/métodos/equipamentos com a expressão "instrumentos complexos", fez a associação no quadro 3 às expressões "gambiarra" e "reagentes vencidos".

Como vemos, todas as respostas convergiram para uma visão kuhniana de ciência (KUHN, 1979, 1998), considerando a "experimentação", a "experimentação em laboratório de pesquisa" e a "experimentação em laboratório didático" como uma atividade de manipulação, afirmando ser possível comprovar a teoria no laboratório, mostrando uma visão de ciência neutra, ateórica, definitiva e quantitativa cujo sujeito isento de julgamento deve reproduzir de forma passiva o que lhe é apresentado. Entende-se que a interpretação dos resultados experimentais sob a concepção indutivista e tecnicista, como a apresentada pelos estudantes analisados, é algo trivial. E ocorre como consequência imediata da realização dos experimentos, limitando o objetivo da experimentação em avaliar a técnica e a precisão do sujeito em seguir roteiros fechados, mesmo que estes sejam teoricamente orientados. 0 resultado disto reflete-se nas respostas que remetem à elaboração de relatórios como a principal atividade da experimentação, resposta recorrente nos três tópicos perguntados.

Quando interrogados sobre a "experimentação em laboratório de pesquisa", os estudantes citaram, além do relatório, a elaboração de artigos e a obtenção de dados como principal atividade, demonstrando mais uma vez uma carência de criatividade, inovação e investigação na experimentação neste ambiente por parte dos estudantes. Em defesa deste argumento, estão as expressões: "como faz esse?" e "muda de cor". Sugerindo que há um roteiro restrito a ser seguido e que há a necessidade de reproduzi-lo corretamente para obter os resultados esperados, não sendo necessários a elaboração de hipóteses e testes para se obter explicações e significações no nível teórico-conceitual. Os alunos também parecem não entender que o roteiro a eles apresentado foi construído a partir de teorias. A expressão "muda de cor" provavelmente esteve associada a práticas com indicadores ácido base. 


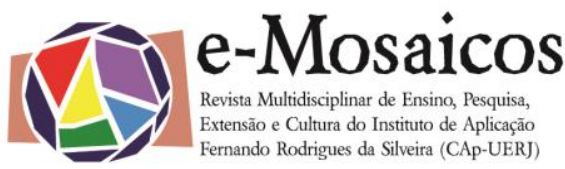

DOI: $10.12957 /$ e-mosaicos.2018.38675

Neste contexto o aluno parece estar mais interessado na cor revelada pela solução do que no entendimento a nível microscópico, ou seja, na reação química que ocorre entre as concentrações iônicas das soluções submetidas a teste e as propriedades halocrômicas dos indicadores.

Ainda houve associações a métodos experimentais específicos e equipamentos de laboratórios de química, cujas técnicas e estratégias de ensino em laboratórios didáticos não são tão rigorosas quanto nos laboratórios de pesquisa, que neste exato momento sofrem com a crise econômica e o sucateamento das universidades públicas. Vemos isto nas expressões: "gambiarra", "reagentes vencidos" e "tanto faz é só para observar" do quadro 3. A estas expressões também encontramos relações com a visão de ciência kuhniana, uma vez que falhas na comprovação de teorias poderiam estar associadas a anomalias e fatores externos à experimentação e à teoria (KUHN, 1979, 1998).

Dentro da mesma concepção de ciência fechada, neutra, pouco crítica e utilitarista, estão as respostas que relacionaram a "experimentação em laboratório de pesquisa" às palavras "inovação" e "tecnologia" e às expressões "parte do que faremos no mercado de trabalho" e "elevar a economia do país", negligenciando processos de validação dos conhecimentos pela comunidade acadêmica e sugerindo que a ciência tem maior poder sob outras áreas do conhecimento. Por outro lado três alunos pareceram estar cientes da potencialidade do uso da experimentação para o ensino além de comprovação de teorias, uma vez que responderam com as expressões "parte do que ocorre na natureza pra dentro do laboratório", "trazer o conceito para algo do cotidiano" e "práticas que podem ser representações de experiências vividas no dia dia", dando a entender ser possível com esta estratégia fazer generalizações e previsões com as teorias aprendidas.

Partindo de todas estas expressões coletadas e das discussões sobre elas, iniciamos a aula que expunha, entre outros pontos, a necessidade de ter objetivos associados à experimentação e fazer um planejamento detalhado das aulas em que será usada a experimentação como recurso didático.

\section{CONSIDERAÇõES FinaIS}

O grupo de alunos analisado parece não ter sido submetido a propostas experimentais que extrapolam a observação empírica, problematizando, tematizando e contextualizando a experimentação. Tampouco parece ter sido levado em consideração que estes alunos serão futuros professores e, que por estarem em um nível avançado de conhecimentos sobre a química, poderiam desenvolver experimentos de maior grau de complexidade interpretativa, como os desenvolvidos em propostas investigativas e suas variantes. Neste sentido concordamos com Espinoza (2010) e entendemos que a interface kuhniana de "experimentação como comprovação de teorias" poderia ser melhor trabalhada. Por exemplo, Se a teoria já houver sido estudada, supõe-se que o experimento deva oferecer a oportunidade de recriá-la, de usá-la como instrumento interpretativo, de reafirmar ideias ou de que se manifestem aspectos ainda não considerados. Quando se propõe o experimento 
e-Mosaicos - Revista Multidisciplinar de Ensino, Pesquisa, Extensão e Cultura do Instituto de Aplicação Fernando Rodrigues da Silveira (CAp-UERJ)

V. 7 - N. 16 - DEZEMBRO 2018 - ISSN: 2316-9303

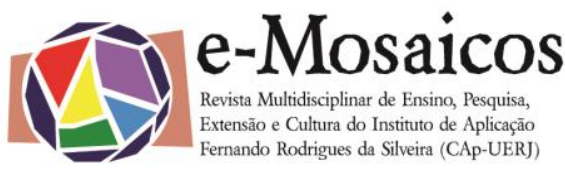

DOI: $10.12957 /$ e-mosaicos.2018.38675

antes de apresentar a teoria, ele supostamente deveria servir de meio para questionar os fenômenos e começar a imaginar interpretações, mesmo que estas não se aproximem do conhecimento científico (ESPINOZA, 2010, p. 120-121).

Outro fator a se considerar é que as atividades de experimentação em laboratório didático e em laboratórios de pesquisa são diferentes, mesmo que ambas sejam de alguma forma teoricamente orientadas. Os motivos, as ações e os objetivos que levam cientistas e estudantes a realizar experimentos não são os mesmos e portanto não concretizam ou provam teorias como os alunos colocaram em suas respostas. Segundo Silva et al (2011), Vemos que a atividade científica de experimentação não concretiza uma teoria. Como toda experimentação, ao contrário ela promove o afastamento do mundo concreto que o homem tem diante de si. Empregá-la como meio de motivar os alunos e facilitar sua aprendizagem pelo suposto fato de que permite concretizar a teoria seria, pois, um equívoco. Além disso, como atividade, ela possui uma finalidade em si mesma, a saber, permite, por sua estrutura e dinâmica, a formação e o desenvolvimento do pensamento analítico, teoricamente orientado (SILVA et al, 2011, p. 240).

Estes autores ainda salientam que, quando fazemos uso de uma teoria para explicar um fenômeno, não significa que estamos provando a veracidade desta, mas sim testando sua capacidade de generalização e previsão. Trocando em miúdos, a capacidade de generalização de uma teoria se daria pela capacidade desta de explicar um fenômeno para a qual ela não havia sido construída ou pensada em sua origem, por exemplo, Ao explicarmos o acender de uma lâmpada ligada à rede elétrica, aplicando o conceito de elétrons (teoria), não estamos provando que esta teoria está correta, mas sim testando sua generalidade, visto que o conceito de elétron foi introduzido, inicialmente, na ciência para explicar a condução de corrente elétrica por gases nos tubos de raios catódicos (SILVA et al, 2011, p. 236).

Neste mesmo sentido, a capacidade de previsão, daria ao experimentador subsídios para formulação de boas hipóteses para testes em atividades investigativas. Por exemplo, se sabemos que uma lâmpada ligada a eletrodos imersos em uma solução contendo íons acende devido à condutividade elétrica da solução, podemos propor que o aumento da quantidade de íons infere na luminosidade da lâmpada, desta forma,

Para testarmos a previsibilidade dessa teoria deveremos ir ao laboratório preparar soluções com diferentes concentrações e observar os resultados. Novamente com essas ações não estamos provando a veracidade da teoria, mas apenas propondo sua capacidade de previsão (SILVA et alli, 2011, p. 237).

Assim torna-se importante estudos de história e filosofia da ciência para conhecer a história dos conceitos, pois a identificação da época, do contexto em que eles foram propostos e, principalmente, que fenômenos eles buscavam explicar nos darão subsídios para boas interpretações, generalizações e previsões. Em suma, são necessários ajustes e refinamentos nas concepções expostas pelos alunos, uma vez que lhes faltam um maior entendimento do papel da experimentação como algo 
DOI: $10.12957 /$ e-mosaicos.2018.38675

teoricamente orientado, cujos motivos, ações e objetivos, dependem diretamente do ambiente em que ela é praticada.

\section{REFERÊNCIAS}

BASTOS, C. C. B. C. Pesquisa qualitativa de base fenomenológica e a análise da estrutura do fenômeno situado: algumas contribuições. Revista Pesquisa Qualitativa. São Paulo, v. 5, n. 9, 2017, p. 442-451. Acesso em 11 jun. 2018, https://editora.sepq.org.br/index.php/rpq/article/view/156.

ESPINOZA, A. M. Experimento na escola: um instrumento de ensino. In: ESPINOZA, A. M. Ciências na escola: novas perspectivas para a formação dos alunos. São Paulo: Ática, 2010, p. 83-122.

KUHN, T. A função do dogma na investigação científica. História e Prática das ciências. Lisboa: Biblioteca de Filosofia, 1979, 75 p.

KUHN, T. A estrutura das revoluções científicas. Coleção Debates Ciência. Tradução: Beatriz Vianna Boeira e Nelson Boeira. 5 ed. São Paulo: Editora Perspectiva, 1998, $256 \mathrm{p}$.

MARTINS, J.; BICUDO, M. A. V. A pesquisa qualitativa em Psicologia. Fundamentos e recursos básicos. 1. ed São Paulo: Editora Moraes, 1989.

MERLEAU-PONTY, M. Fenomenologia da percepção. Tradução Carlos Alberto Ribeiro de Moura. São Paulo: Martins Fontes, 1999.

OLIVEIRA, J. R. S. Contribuições e abordagens das atividades experimentais no ensino de ciências: reunindo elementos para a prática docente. Acta Scientiae. v. 12, n.1, 2010, p.139-153. Acesso em 02 fev. 2018, http://www.periodicos.ulbra.br/index.php/acta/article/view/31.

SILVA, R. R; MACHADO, P. F. L.; TUNES, E. Experimentar sem medo de errar. In: SANTOS, W. L. P.; MALDANER, O. A. Ensino de química em foco. Ijuí: Editora Unijuí, 2011, p. 231-261.

Recebido em 05 de dezembro de 2018

Aceito em 15 de dezembro de 2018 